\title{
OS DEMÔNIOS DO GOZO: UMA CONTRIBUIÇÃO PARA A PSICANÁLISE DA ESQUIZOFRENIA
}

Angela Pequeno

Psicanalista, membro da Delegação GeralNatal da Escola Brasileira de Psicanálise; doutora em Ciências da Saúde (Área de Concentração em Psicanálise) pelo Instituto de Psiquiatria da UFRJ.
RESUMO: Relato da análise de um sujeito psicótico. 0 lugar conferido à analista pela transferência permitiu-Ihe ser testemunha de um doloroso processo de derrocada subjetiva que, no entanto, sempre coexistiu com uma tentativa de cura e reconstrução que tinha algo de heróico. Ao perceber o progressivo abandono por parte da instituição, o paciente passou a construir uma seqüência de monstros em contraponto às suas vivências no hospital psiquiátrico. Os demônios têm uma vertente simbólica, são nomes para o gozo. Possibilitam também uma reconstrução do imaginário, na medida em que efetuam alguma separação entre o eu e o outro. A construção dos demônios constitui um trabal ho com o real, um esforço para barrar o gozo do Outro que ameaça dissolver a estrutura do sujeito. Assim, ao menos durante certo período, foi possível estabelecer e manter alguma distância entre o campo do sujeito e o campo do Outro, efetuando-se uma recomposição, embora fugaz, do nó pelo qual o sujeito se sustentava na existência.

Palavras-chave: Psicanálise, sujeito, psicose.

ABSTRACT:The demons of jouissance: a aontribution to the psychoanalysis of schizophrenia. This paper reports on the analysis of a psychotic subject. Transference enabled the analyst to witness a painful subjective debacle process which, however, ran in parallel with a heroic attempt at cure and reconstruction. As the subject perceived that the institution was letting him down, a whole series of monsters began to be constructed as related to his psychiatric hospital experience. The demons have a symbolic dimension and are in fact ways of naming jouissance. They also permit a reconstruction of the imaginary, inasmuch as they effect a separation of the subject from the other. Demon construction constitutes a way of working with the real, an effort to deter the Other's jouissance which threatens to break up the subject's structure. Thus, at least for some time, the subject was capable of establishing and maintaining some distance between himself and the other and of reconstructing, though briefly, the knot on which his existence was sustained.

Keywords: Psychoanalysis, subject, psychosis. 
0 mundo jamais é inumano porque é composto pelo homem.

LACAN, 1955-1956

$\mathrm{O}$

ujeito constitui a dimensão específica em que a psicanálise opera. 0 campo do sujeito é coextensivo à psicanálise. Reconhecer no psicótico um sujeito é, portanto, condição essencial para abordá-lo pela psicanálise. Inversamente, não ceder diante da psicose faz o analista avançar em sua concepção acerca do sujeito: "a psicoseé uma questão de sujeito porque nos conduz aos confins de sua produção" (MILLER, 1987, p.181). 0 caso que apresento a seguir ${ }^{1}$ vem ao encontro desta afirmação.

Fabrício procurou uma psicoterapia após ter passado meses internado em um hospital psiquiátrico. 0 motivo foi sua agressividade, depois dirigida à esposa, a quem dizia amar muito. Sentia uma ira que não controlava.

Contou-me então que seu primeiro surto ocorrera há dez anos. No dia em que conhecera a esposa e a convidara para ir até sua casa. Assim que ela saiu, sua mãe Ihe disse que ela não servia para ele.

Começaram a namorar. No período que antecedeu o casamento, sua mãe Ihe telefonava todos os dias, dizendo: "não deixe que ela tire vocêde mim". Seis meses depois de casado, Fabrício teve o primeiro surto, caracterizado por episódios de violência em seu local de trabal ho. Depois, perdeu a consciência, não se lembrava de mais nada. Sua esposa telefonou para a mãe dele para comunicar-Ihe o que estava ocorrendo e ela Ihe respondeu: "eu dei meu filho para vocêbom, só quero recebêlo de volta bom".

Esse sujeito era o objeto exclusivo e absoluto da mãe. Fabrício sofria de uma triangulação impossível. Mais tarde, ele me diria que o surto "já estava escrito".

A situação desencadeadora da psicose seria o encontro com Um-pai:

"Que se procure no início da psicose essa conjuntura dramática. Quer ela se apresente, para a mulher que acaba de dar à luz, na figura de seu marido, para a penitente que confessa seu erro, na pessoa de seu confessor, para a mocinha enamorada, no encontro com o 'pai do rapaz', sempre a encontramos, e a encontraremos com mais facilidade ao nos guiarmos pelas 'situações' no sentido romanesco desse termo." (LACAN, 1957-1958/ 1966, p. 578)

\footnotetext{
${ }^{1}$ Segue-se um dos dois casos clínicos que foram construídos para minha tese de doutorado, "Sujeito e psicose" (PEQUENO, 2000). Ambos foram atendidos no Instituto de Psiquiatria da UFRJ; do ponto de vista do diagnóstico estrutural, eles se incluem nas categorias da esquizofrenia e da paranóia. Eles foram escolhidos porque constituem exemplos paradigmáticos. Presentificando as duas vertentes que abordo na tese, a desconstrução e a reconstrução do sujeito na psicose possibilitam adentrar os meandros desses processos.
} 
0 primeiro surto foi uma catástrofe subjetiva, da qual Fabrício não se recuperou. Passou a viver, durante nove anos, como que internado em casa, a esposa assumindo o lugar que antes a mãe ocupava. Fabrício, cujo parco conhecimento de psicanálise era aguçado por seu rigor de psicótico, sabia que tinha feito uma transferência da mãe para a esposa.

Em 1996, teve o segundo surto, caracterizado por cenas de violência contra a esposa, e passou dez meses internado. Sabia do que fez através dela, pois não se lembravadenada.

Jána segunda entrevista, Fabrício disse que eu o irritava. Meu silêncio lembravaIhe sua mãe, que ficava cal ada quando queriairritálo; meu jeito de falar também.

$N$ a terceira entrevista, chegou pedindo um outro terapeuta. Não estava gostando do meu silêncio. Respondi que seu pedido poderia ser atendido, mas propus que ele viesse na sessão seguinte.

Para este sujeito psicótico, a "irritação" éo significante da transferência (LACAN, 1967). No entanto, não se verifica a suposição de saber à analista, no sentido que a mesma assume na psicanálise de neuróticos. Isto é, neste caso, a suposição de saber não diz respeito aos significantes da cadeia inconsciente, mas seria uma suposição de saber fazer com 0 gozo. 0 pedido à analista, que Fabrício reiterava nesse momento, era controlar a ira dirigida à esposa, que estaria corroendo o ponto de sustentação de sua existência.

Com a emergência desse significante, Fabrício entrou no trabalho analítico. A irritação era a resposta que ele emitia a partir de uma posição de objeto. Esse foi o momento em que ele me incluiu na transferência, constituindo uma série psíquica: a mãe $\rightarrow$ a esposa $\rightarrow$ a analista. Quando escutei seu pedido, fazendo intervir o desejo do analista, reconheci nele um sujeito. A partir daí, dissolveu-se a transferência negativa cuja intensidade ameaçava inviabilizar o trabalho. Consegui assim preservar a análise de sua agressi vidade.

O significante do laço que ele então estabeleceu comigo foi " nossas conversas" ou, com menos freqüência, "nossa terapia". Si gnificante preciso, em que cadatermo, o laço e a fala, têm um valor. M esmo nos momentos mais graves e pungentes da análise que então se iniciou, Fabrício nunca deixará de afirmar que "nossas conversas" o estão ajudando a se conhecer, a controlar sua ira.

Quando decidiu permanecer no tratamento, Fabrício passou a trazer elementos de sua história. Esta parecia ter sido al vo, não de uma contínua ressignificação como ocorre na neurose, mas de uma verdadei ra remodelação, que se pusera em movimento a partir da eclosão da psicose.

Sua relação com a mãe - relação exclusiva que o sustentara na existência era definida pela expressão: "carícias negativas". . Desde criança, quando brigava com ela, sumia pelo mundo e fazia coisas de que não se lembrava depois. Ficava sabendo por terceiros que tinha se envolvido em "episódios bissexuais" (isto é, 
ora com homem, ora com mulher). Em três anos, chegou a sair com cem ou duzentas meninas, quase todas virgens. Ao pensar nisso ficava triste, pois quando estava "localizado na razão" não fazia nada disso.

Quando se afastava da mãe, ocorriam as ausências, os lapsos de memória, que preenchia com essas construções em que os produtos da atividade imaginativa se mesclam a idéias delirantes, as quais, como sabemos, se apóiam em fragmentos da história(FREUD, 1937/ 1980).

Na esquizofrenia não ocorre a simbolização da ausência da mãe tal como se dá na paranóia. A mãe funcionou para Fabrício como bengala imaginária. Quando ela não estava presente, el e se perdia. Após a ruptura dessa sustentação, ele passou a fabular suas ausências. Atualmente acontecia al go análogo: sua esposa não podia deixá-lo sozinho, pois aí ele corria o risco de sair errando, sem destino. Confessou-me que fazia "o possível para parecer localizado, mas é perdidinho".

Nessas passagens, Fabrício apresentava sua errância de psicótico. As duzentas virgens traduzem a invasão de um gozo infinito, sem o basta do Nome-do-Pai.

Um mês depois do início do tratamento ambulatorial, Fabrício foi internado, devido à intensificação da violência dirigida contra a esposa. No decorrer da análise pude confirmar minha hipótese quanto ao motivo dessa internação, assim como da anterior: a relação teria se desestabilizado porque a esposa, cansada de sua função de enfermeira, o estaria deixando cair.

A esposa era para ele a única referência. Só contava com ela no mundo, ela era seu ponto de apoio na vida. Para me mostrar como era assim, pôs um dedo sob a mão estendida. A mão, explicou-me, era como se fosse seu mundo e o dedo que a sustentava, sua esposa.

Lacan compara o mundo de um sujeito a um tamborete cujos pés são os significantes fundamentais. "N em todos os tamboretes têm quatro pés. Há os que ficam em pé com três. Mas então, não pode faltar mais nenhum, se não a coisa vai mal" ( LACAN, 1955-1956, p. 228). 0 mundo de Fabrício se sustentava num tamborete de um pésó.

Na esquizofrenia, a representação do sujeito pelo significante está comprometida. Fabrício se sustenta pelas bengal as imaginárias. Sua imagem é precisa e rigorosa: o que sustenta seu mundo é, não a armação significante, mas sim a bengala imaginária que a esposa representa para ele ou, antes dela, sua mãe representara.

Nessa medida, a instituição vem ocupar o lugar do qual a esposa se retirava, formando-se assim a série: a mãe $\rightarrow$ a esposa $\rightarrow$ a instituição. Eu fiquei fora dessa série, pois a ira de Fabrício foi dirigida a outros el ementos da instituição. Foi assim possível preservar meu lugar de analista.

Um dia, quando ele me falou mais uma vez da transferência que efetuara da mãe para a esposa, disse: "a raiva é da mãe". Assinalei o duplo sentido de sua fala e ele então me contou as circunstâncias de seu nascimento: nascera de uma relação 
em que sua mãe fora estuprada pelo pai, de quem estava separada na época da gravidez. Seu pai queria que ele nascesse, sua mãe não. Aí, como sempre, prevaleceu a vontade da mãe. Ao questionar essa revel ação estarrecedora, verifiquei que não se tratava de um lapso, mas de uma constatação lúcida.

Para o sujeito, naître equivale a n'être, nascer é não ser (LACAN, 1961-1962; OGILVIE, 1988). N esse sentido, Fabrício não nascera. Com o rigor que caracteriza sua condição de psicótico cujo corpo épalco do gozo do Outro, ele me falou desse impasse em sua constituição como sujeito.

Contou um episódio ocorrido quando tinha dois anos e meio: ol hara para sua mãe e vira um olhar de ódio. Depois disso, nunca mais fora o mesmo. Diz Lacan: "não é fácil dizer o que é um olhar. É algo que pode muito bem sustentar uma existência ou devastá-la" (LACAN, 1968-1969, 26/3/69).

$\mathrm{N}$ a enfermaria, as crises de Fabrício consistiam em se arremessar violentamente contra a porta de saída, golpeando-a com a mão e com a cabeça. Esses episódios eram acompanhados de perda de consciência. Só voltava a si quando estava sendo medicado. Mas lembrava-se de sentir uma ira fortíssima, que o deixava cego. Tentei interpelá-lo, mas ele insistiu: "é como lodo, não entraluz nenhuma".

Quando fal ta o vetor do desejo, quando não há a inscrição do vazio, o sujeito oscila entre a abulia e a passagem ao ato. Era esse o caso de Fabrício.

As amnésias são furos na cadeia significante. Nesse distúrbio maciço da memória, vemos a desarticulação do simbólico. A ira é um nome para o gozo do Outro que nesses momentos invade o sujeito.

Fabrício tentou controlar o impulso agressivo mediante "um esforço monumental"; quando não o conseguia, inseria significantes no lodo da vivência, em busca de uma elaboração.

Dessa época, alguns episódios são compreensíveis. Era comum, por exemplo, que ele tivesse uma crise após uma visita da esposa, que sempre Ihe dizia algo rejeitador. Pude também observar que suas ameaças ou ataques concretos, fora da crise, a médicos ou a outros pacientes, sempre tiveram al gum fundamento.

Foi durante esse período que ele começou a falar das vozes que escutava continuamente. Revelou que agora estava prestando mais atenção a elas, pois ele próprio tinha quem o escutasse. A constituição do lugar do analista possibilita ao sujeito encontrar significantes para o gozo. As vozes eram acompanhadas de descargas elétricas que iam de uma orel ha para outra. Às vezes conseguia entendê-las, às vezes não. Quando as entendia, elas diziam: “ataque!", " destrua!" . E aí conseguia se opor. Quando não as entendia, era mais perigoso.

U m dia, reconheceu a voz do irmão (mais do que a voz, o jeito de falar); num outro dia, as vozes eram "várias e desconhecidas". Ou seja, são vozes que tinham uma alteridade e não pensamentos auditivados que ele poderia reconhecer como seus. 
Fabrício foi piorando, o que atribuí a uma série de razões. Entre elas, ao desenvolvimento de idéias delirantes de perseguição em relação a seu psiquiatra. Logo após um exame médico, que sentira como extremamente invasivo, ele me falou de sua atração sexual pelo psiquiatra; em seguida, este se deslocou de uma série paterna, mais acolhedora, para a série materna, e a perseguição se desencadeou. Além disso, Fabrício estava percebendo com maior clareza o abandono por parte da esposa. Não falava claramente sobre isso, mas o manifestava de al gumas maneiras. Passou a não reconhecê-la e chamá-la de "doutora da roupa", com referência a uma das funções que ela ainda desempenhava em seu cotidiano. Vi nisso também uma maneira de barrar sua agressão dirigida a ela.

Se antes ele fal ava sobre o gozo, agora este passava a se presentificar em sua fala, interrompendo-a. 0 gozo se apresenta sobretudo como um riso do tipo que os psiquiatras chamam de imotivado.

Começou a falar em suicídio como solução para sua vida. Disse tentar o suicídio desde criança. Bebia detergente, água sanitária... Divertia-se com a cara dos médicos, queolhavam para ele preocupados, perguntando por queteria feito aquilo. Gostava também de botar fogo no colchão. Essas narrativas eram interrompidas por risos desproporcionais.

Em termos do nó borromeano, essaémaisuma evidência daruptura dos registros, ficando solto 0 elo do real - o que se manifesta também nos arremessos contra a porta da enfermaria. Fabrício tentava restaurar a articulação dos registros mediante uma reconstrução retrospectiva de sua história. Tipicamente, projetava no passado elementos do presente, visando a estabelecer uma continuidade temporal.

Quando voltei de férias, ele custou a se lembrar de mim. Reafirmei a convicção de que de al guma forma ele se lembrava. Dias depois, declarou: "Vocêvem conversar comigo. Isso quer dizer que não estou abandonado."

Surgiu uma nova fantasia gozosa: queria matar gatinhos e pombinhos, darIhes comida para que voltassem a viver, e depois matá-los de novo... Queria ver sangue. Queria sorvete de gatinho, sorvete de pombinho... Sempre ria quando falava disso. "Se o seu sangue cair na terra, será que podem nascer bichinhos?"

A concepção de que o sangue poderia fecundar a terra, para esse sujeito, parece advir como efeito daforaclusão do Nome-do-Pai eda conseqüente carência fálica. 0 falo localiza o sujeito na partilha dos sexos como homem ou mulher. 0 sangue não traz a marca dessa diferenciação. Nascido de um estupro, que derrama sangue, Fabríci o seria então fruto do sangue, e não do sêmen.

Quando, ao se separar da mãe, ele criou cenas em que estuprava virgens, estaria efetuando uma identificação imaginária com seu pai?

Se o sangue fertiliza - são suas próprias palavras - , será que beber sangue é uma fantasia de ser copulado para além do falo? U ma manifestação do empuxo à mulher? 
Um dia, já decorridos seis meses de internação, encontrei-o assustado. Contou-me que viera um auditor Ihe dizer que ele estaria ameaçado de alta administrativa por ter batido em uma médica.

Esse "auditor" era, de fato, o diretor clínico do hospital. Quanto ao ato agressivo de Fabrício, ele fora dirigido à psiquiatra que tinha ido buscá-lo para uma apresentação de pacientes - ele se recusava a ir e foi levado "no susto". Mais uma vez, o comportamento agressivo de Fabrício fora motivado. Reagira contra um ato de violência institucional e provocara, em resposta, um outro ato de violência institucional. Mas, como costuma acontecer em casos semelhantes, a pecha de violento coube a ele.

Detalho esse evento porque me parece que ele contém o germe de muito do que irá se suceder no tocante à instituição. A permanência de Fabrício desafiava as concepções de cura e o saber médico. 0 diagnóstico oscilava, sem se firmar, entre esquizofrenia, epilepsia ou mesmo um grave transtorno dissociativo, histérico. Além disso, se a remissão de sintoma não se dá com presteza, supõe-se que a internação esteja tendo um efeito cronificador sobre o paciente. Ou seja, assim como a esposa, a instituição não o estava sustentando. Esse foi, a meu ver, o determinante fundamental da direção que o caso tomou.

Começou nessa época uma série infindável de questionamentos: “Por quetomamos banho com sabonete e lavamosa cabeça com xampu e não o contrário? Por que sai água da torneira e não refrigerante?" Perguntas que incidem sobre elementos básicos da realidade, cujo contorno, como sabemos, é simbólico. Elas indicam um desatrelamento do significante, evidenciam que o elo do simbólico está solto. Para Fabrício, a reali idade e seu contorno simbólico não estavam se sustentando.

Em vários momentos deste relato clínico, pontuei fenômenos que demonstram que o nó pelo qual Fabrício se sustentara na existência estava se desfazendo. ${ }^{2}$

0 desatrelamento do simbólico inclui, além das vozes que fazem do mundo desse sujeito um viveiro de pássaros, ${ }^{3}$ as amnésias e as perguntas que dirige à analista, concernentes aos significantes que contornam o campo da reali idade. A ruptura do elo do real se manifesta nas passagens ao ato enos acessos de riso desconectados do significante. 0 elo do imaginário é sustentado pela esposa ou pela instituição psiquiátrica, que estavam se retirando.

\footnotetext{
2 Desde o início do ensino de Lacan (1953-1954/ 1975), está presente a concepção de que a qualidade específica da experiência humana é dada pela articulação dos três registros heterogêneos que são o imaginário, o simbólico e o real. Em sua última formulação (1975-1976), Lacan passa a considerar esses registros como sendo equival entes, interdependentes cada um dos outros e dependentes da articulação de um nó que os enlaça. 0 desencadeamento da psicose faz com que os elos que compõem o nó se desprendam deste. As várias modalidades de tentativas de cura que a partir de então se colocam em ação correspondem a tentativas distintas de recompor o nó.

${ }^{3}$ Essa expressão foi trazida em uma discussão clínica por François Leguil.
} 
Ao assistir ao noticiário na televisão, esta tentou sugá-lo para seu interior, para matá-lo. Decidiu que não mais veria televisão. Rompeu-se mais um elo de sua ligação com os humanos.

U m dia, recebeu-me al egremente, dizen do que era seu aniversário. Estava fazendo três aninhos. Estava na creche, ganhara uns bolinhos... descreveu os remédios. Gostava de seu bercinho. Não queria sair dali. Ficava de quatro, olhando as formigas. As vozes Ihe diziam que devia observar as formigas. Elas deviam ter razão.

Quando ele diz: "estou fazendo três aninhos", parece-me que há todo um endereçamento aos médicos eaos burocratas, um pedido institucional, mas há também um grande rigor. É uma maneira de falar de uma regressão profunda.

A partir de então, tornaram-se freqüentes suas referências à creche. E passou a brincar de controle remoto com formigas. Penso que, possivelmente, se identificou com elas: é como se fosse uma formiga teleguiada sonhando com a liberdade.

Essas e outras produções de Fabrício são mesclas de elementos fantasiosos e de idéias delirantes e se apóiam em diversas modalidades de alucinações verbais (auditivas, visuais, cenestésicas). Elas são construídas em contraponto às suas vivências no hospital psiquiátrico, a partir do valor simbólico que estas adquirem para ele, e mefazem pensar em uma versão esquizofrênica do teatro particular deAnna 0 . São frágeis tentativas de cura, a partir das quais Fabrício não consegue sistematizar uma construção que o estabilize.

Como o eu está posto fora de ação, Fabrício não consegue discernir a fantasia da real idade. Além disso, parece-me que os dois planos da realidade em que vive - nesse exemplo, a crechee o hospital psiquiátrico - permanecem em compartimentos estanques. Aquilo que para o neurótico poderia aparecer uma divisão não se articula na psicose em virtude da foraclusão do Nome-do-Pai. No entanto, esses fenômenos produzem, para quem os observa, um semblante de divisão que aumenta a possi bilidade da confusão diagnóstica entre esquizofrenia e histeria.

$\mathrm{N}$ a véspera de $\mathrm{Natal}$, contou-me um sonho, e a partir daí se lembrou de que tinha este sonho desde criança. Sonhou com um animal grande, peludo e de chifres. Ele lhe dava ordense ele as obedecia.

Esse animal o acompanhava desde criança. Era el e que o fazia irritar sua mãe e mais tarde maltratar a esposa. Achava que ele era o diabo. 0 diabo eram nossos defeitos. Eram dele as vozes que ouvia, desde criança, dizendo-Ihe para atacar e destruir.

Naverdade, émais do que um sonho: ele também escuta e vêesse animal etem que obedecer a ele.

O bicho peludo é uma figura do gozo. Fabrício assim nomeia o gozo, numa tentativa de localizá-lo. Reitera que o bicho peludo está menor. Com a internação e nossas conversas, estava conseguindo controlar sua agressividade. Ainda muito pouco, masjá eraum passo. 
Apesar da gravidade de sua condição - há um perigo de apagamento do sujeito - Fabrício se lançou com dedicação a um trabalho com a fala. Por vezes, era de uma enormelucidez. Reconhecia, por exemplo, que havia dez anos viviaum surto contínuo. Atual mente, o máximo que conseguia ter eram surtos de lucidez dentro do surto deloucura.

Em sonhos e fantasias, Fabrício passeou com a grande árvore do pátio da enfermaria. U ma noite ela o levou até Salvador; em outra ocasião circundou com ele a Estátua da Liberdade.

Um dia, sonhou que estava conversando comigo no mesmo banco em que costumava atendê-lo no pátio da enfermaria e as tel has viravam tel has vampiras. Elas criavam dentes e partiam voando para cima de nós. Conseguiu fugir correndo para o posto de enfermagem.

Essa foi a primeira vez que ele relatou um sonho comigo. Perseguido por um Outro implacável, Fabrício reservou para a analista o lugar de companheira.

Tanto o bicho peludo como as tel has vampiras foram inicialmente produzidas em sonhos. Depois, mantiveram uma existência na vigília.

Freud compara o sonho à esquizofrenia, dado o caráter alucinatório desta afecção. ${ }^{4}$ Nesse paciente esquizofrênico, sonho e vigília estão em continuidade. Os sonhos de Fabrício têm o mesmo conteúdo que suas fabulações autísticas, são ambos produzidos a partir das vivências no hospital psiquiátrico.

Fabrício sonhou com o dragão do rei.Tal monstro se manifestara havia pouco tempo e queria tirá-lo daquela creche para levá-lo para outra. No sonho, ele brigava com o dragão do rei e conseguia vencê-lo, mas saía todo machucado.

Traduzo: ele queria lutar para ficar na instituição onde estava.

Esta era uma escolha do sujeito - que não se sustentou.

Ao contar outro sonho, produziu-se um lapso: "Sonhei com o monstro alto. Ele me dava um pontapé e dizia: Aqui você não entra mais." Quando falou sobre esse sonho, verifiquei que sua intenção era dizer "moço". "Moço alto" era como ele costumava chamar o diretor clínico. Ficava então claro para mim que o Dragão do Rei era o diretor clínico, o mesmo que o ameaçava com a alta administrativa e a transferência para outro hospital.

Como pensar essa seqüência de monstros? Ao perceber que a instituição também poderia desertá-lo, ele recorreu a um enxame de significantes. A pluralização

\footnotetext{
${ }^{4}$ Em Complemento metapsicológico à doutrina dos sonhos ( 1917 [ 1915]/ 1979), Freud afirma que tanto o sonho quanto a esquizofrenia são caracterizados pela regressão temporal: o eu regride ao estágio do narcisismo e a libido, à etapa da realização alucinatória de desejos. 0 que diferencia o fenômeno normal do patológico é a ausência, neste último, da regressão tópica, isto é, do pré-consciente ao inconsciente, a qual fica inviabilizada por ter o processo defensivo atingido as representações de coisas do inconsciente (FREUD, 1915/ 1979).
} 
dos $\mathrm{S}_{1}{ }^{5}$ nesse analisando esquizofrênico aponta para a ausência deste termo. É uma tentativa de instaurar um vazio - em vão, já que, para ele, todo simbólico é real (FREUD, 1915/ 1979; LACAN, 1954/ 1966; MILLER, 1985). ${ }^{6}$ Eraa partir da constituição desse vazio que o sujeito poderia se sustentar.

A queixa de ouvir vozes se intensificou. Quando elas Ihe diziam para matar, respondia: "matar não". Mas, em sonhos, obedecia. Era muito desejo de matar. "Desejo de quem?" , perguntei. Não sabia; das vozes. Deixei isto como questão na qual ele talvez pudesse pensar.

Durante uma sessão, assustou-se. Havia um vampiro atrás de sua orelha direita, querendo chupar seu sangue. Esse vampiro, que ele não conseguia ver nem tocar, passou a ser uma presença habitual na vida de Fabrício.

U ma sessão subseqüente inaugurou um marco. Nela deu-se um passo decisivo ${ }^{7}$ no sentido de barrar o gozo do Outro. Conversando com a voz, Fabrício repetiu al gumas vezes: "sangue humano, não". Perguntei a ele do que se tratava: o vampiro estaria Ihe dizendo para ele cortar meu pescoço e beber meu sangue. Reiterei: sua resposta foi não.

A partir daí, esse diálogo com a voz se tornou habitual. Fabrício passou a levar uma garrafa d'água para a sessão. Quando o vampiro Ihe dizia para beber meu sangue, respondia: "Quer sangue?" - e bebia a água. Um dia, sublinhei: "Vocêo engana." Fabrício me respondeu, rindo: "Sim, esses demônios são muito burros."

Ele conseguiu aí introduzir al guma barra no Outro, de quem o vampiro é uma figuração. Cabe ao psicótico, sujeito do gozo (LACAN, 1966), fazer a lei do Outro. Fabrício não consegue construir um conceito elaborado e estável como o da Ordem do Mundo de Schreber, que faz suplência da lei. Só Ihe resta o recurso ao engano.

A burriceéumafalta, de inteligência ou de esperteza. Momentaneamente, o sujeito consegue "constituir a hiância de um vazio". Mas, paraFabrício, "todo simbólico éreal" eo engano, vão. E assim éque os demônios vão se tornando mais e mais poderosos.

Pouco depois, inaugurou-se uma série de sonhos de enterros. 0 único enterro ao qual Fabrício de fato compareceu foi o de seu pai. Sentira então um misto de tristeza e de estranha al egria.

Os personagens desses sonhos, que testemunham o animismo crescente que invade o mundo do sujeito, são os objeto inanimados que o circundam na enfermaria. Tipicamente, uma pilastra está no caixão, para ser enterrada. Ao enterro comparecem pilastras, telhas e lajotas.

\footnotetext{
${ }^{5} \mathrm{~S}_{1}$, em francês faz homofonia com essaim, enxame.

6 "O esquizofrênico busca constituir a hiância de um vazio. Em vão, porque para ele todo simbólico é real" (LACAN, 1954/ 1966, p. 92).

${ }^{7}$ Esse passo, infelizmente, não se sustenta. Como já dissemos, além de sua gravidade, motivos de ordem institucional tiveram um enorme peso no desenlace do caso de Fabrício, mas não iremos aqui nos alongar sobre eles.
} 
Em um desses sonhos, um poste do pátio tinha morrido. 0 caixão era em forma de cruz, como o próprio poste. Durante o enterro uma telha caiu dentro do caixão e se espatifou. Fabrício sabia que era um suicídio.

Nessa época, queixou-se de estar triste. Sobretudo após os sonhos com enterros, acordava deprimido, com uma sensação de morte, como se a morte o estivesse rondando.

Teve início uma nova série de sonhos. Sonhou que estava deitado e chegavam o dragão do rei e o vampiro, arrancavam seu coração, dividiam-no em dois e cada um comia uma metade. Acordava angustiado.

Outro sonho terrorífico: o dragão do rei vinha por trás, pegava-o pelo pescoço com as garras e levava-o até a pedra que se via da enfermaria, deixando-o cair de uma grande altura. Ele ainda estava vivo mas sem conseguir se mexer, quando 0 monstro se aproximava e ficava comendo seus braços, suas pernas, seus órgãos internos. E ele sentia toda a dor.

Em sua tentativa de reconstruir o mundo, o esquizofrênico recorre às palavras, mas não consegue fazê-las ancorar-se sobre o corpo. Sem a mediação da linguagem, o corpo real fica confrontado ao real do gozo do Outro. Esses sonhos, que me evocam a violência dos rituais astecas, o demonstram.

Asconstruções de Fabrício serevelam insuficientes, inadequadas para barrar o gozo.

É só depois dos sonhos em que as coisas do mundo se suicidam que surgem esses sonhos mortíferos, ápice da dissolução imaginária, em que o corpo do sujeito é desmembrado e seus órgãos tomados como objeto do gozo do Outro. Essa é uma hipótese, mas ela se impõe.

Mesmo nesse momento de perigo máximo, Fabrício reconhecia que nomear as vozes anônimas constituía um caminho. Os monstros, frágeis pontos de sustentação de sua existência como sujeito, eram construídos sob transferência.

Surgiu, então, o bebêvampiro: ele era muito mau, ficava no bercinho chupando ovo de cobra, de morcego... À noite, vinhalamber o pescoço de Fabrício, preparar a mordida. Se ele o derrubasse da cama, voltava a subir. Era muito forte.

A psiquiatra que, a pedido do próprio Fabrício, tinha assumido seu caso, estava grávida. Ele via isso, com muito senso de realidade, como uma enorme ameaça à sua permanência na instituição. 0 bebê vampiro era, assi $m$, uma encarnação do mal.

U m dia, encontrei-o na cama. Não fez nenhum gesto para se levantar, parecendo em estupor. Consegui que dissesse apenas quatro frases, que seguiram o mesmo padrão. Cito uma delas: "aquela porta vai explodir" (apontou para a janela). Disse ainda, segurando a cabeça com ambas as mãos: "dor".

Procurei indagar o que teria havido efiquei sabendo que Fabrício recebera um bilhete endereçado à sua esposa, convocando-a para uma reunião com o diretor clínico. Não sabemos se ele teria lido o bilhete, ou em que termos a esposa lhe teria 
falado de seu conteúdo. De qualquer maneira, levando-se em conta o que estava ocorrendo na instituição, o desenlace não poderia ter sido diferente do que foi.

Aos poucos, surgiram indícios de que a relação transferencial estaria preservada ou, pelo menos, sendo retomada. Em uma ocasião, ele encostou a cabeça no travesseiro e fechou os olhos, o que tomei como indicativo de que estaria encerrando a sessão, como de hábito. Outra vez, quando cheguei no horário combinado, tive a impressão de que estava me aguardando. Ao Ihe perguntar como estava, obtive como resposta: "arrebentado" . Ejustificou: "aquelas tel has caíram do chão" ( olhou o teto) "e mergulharam no teto" (olhou o chão).

As poucas frases que Fabrício enunciou foram indicativas de um profundo desmantelo do simbólico. Era como se ele retomasse as perguntas que me fizera antes, mas agora afirmando o lado que antagonizava o simbólico.

Aos poucos, seu pensamento foi ficando mais organizado. Nessa época, ele assim comentou o nascimento do filho da psiquiatra: " $O$ bebê vampiro tem perturbado muito. Ele estava preso num subterrâneo do castelo. A princesa gostava dele, mas o carcereiro, não." Contou também que estava sendo perseguido pela mamadeira envenenada. Ela queria que ele a bebesse. Depois, ele se refugiou em seu quarto e conseguiu escapar. Assinalei, tentando colocar algum limite, que algo ele conseguiabarrar.

Lembrei-Ihe de que me tinha dito que os demônios eram burros. Não daria então para el e os vencer? Fabrício então revel ou que por trás deles estava a Cabeça de Legião, que pensava por todos. Nessa época, el e já sabia que o diretor da instituição estava se ocupando de seu caso.

Falou-me então da última batal ha que estava para travar contra o demônio. Se perdesse, perderia sua alma e nunca mais veria sua amada. Se vencesse morreria, mas estaria livre do demônio e livraria dele a humanidade. Enquanto nossos atendimentos durassem - pela primeira vez mencionou a possibilidade de sua interrupção - , queria falar de sua luta contra esse demônio, o mais forte de todos. N esse momento, mudou subitamente de registro, fal ou da realidade factual. Não sabia quanto tempo permaneceria ali, pois, sendo aquele um hospital-escola, os pacientes ficavam por pouco tempo.

Entre os dois termos dessa seqüência, pareceu-me não haver uma associação no sentido neurótico; a visada associativa, nesse caso, equival eria a uma tentativa de compreensão por parte daquele que escuta. Embora possamos observar que 0 que se passa na realidade tem efeitos sobre o mundo autístico de Fabrício e viceversa, a conjunção entre ambos é mínima. Sobretudo, não há possibilidade de dialetização. ${ }^{8}$

\footnotetext{
${ }^{8}$ Segundo Bleuler (1971), que introduziu a esquizofrenia e o autismo no vocabulário psiquiátrico, os esquizofrênicos perdem em maior ou menor grau o contato com a realidade e "vivem
} 
Em uma de nossas últimas conversas, Fabrício explicitou sua posição subjetiva. Sabia que era culpado do que estava lhe acontecendo. Sempre fora covarde, deixara-se manipular pelos demônios.

Nessa época, seu destino já estava selado: ele seria transferido para outra instituição.

Não pude me despedir dele. Asúltimas palavras que dele escutei foram: “o rato está comendo o gato", e "a vingança será terrível".

Recebido em 19/ 2/ 2002. Aprovado em 8/ 5/ 2002.

\section{BIBLIOGRAFIA}

BLEU LER, E. (1971) Tratado de psiquiatría, 3. ed., Madri, Espasa-Calpe. FREUD, S. (1979/1980) Obras completas, Buenos Aires, Amorrortu.

(1915) “Lo inconciente", v. 14, p. 153-214.

(1917 [1915]) "Complemento metapsicológico a la doctrina de los sueños", v. 14, p. 215-234.

(1937) "Construcciones en el análisis", v. 23, p. 255-270.

LACAN, J. ( 1953-1954/ 1975) Le Séminaire, livre I, Les écrits techniques de Freud, Paris, Seuil.

. (1954/ 1966) "Réponse au commentaire de Jean Hyppolite sur la 'Verneinung' de Freud", in Écrits, Paris, Seuil.

. (1955-1956/ 1981) LeSéminaire, livrellI, Les psychoses, Paris, Seuil. . (1957-1958/1966) “D’une question préliminai reà tout traite-

ment possible de la psychose", in Écrits, Paris, Seuil.

. (1961-1962) L'identification. Seminário inédito.

. (1966/ 1986) "Présentation des Mémoires du président Schre-

ber en traduction française", in Ornicar?, n. 38, Paris, Navarin, p. 5-9. (1995) "Proposição de 9 de Outubro de 1967: 1ạ versão", in

Documentos para uma Escola II - Lacan e o Passe, Rio de Janeiro, Letra Freudiana.

. (1968-1969) D'un autre à L'Autre. Seminário inédito.

(1975-1976) Le sinthome. Seminário inédito.

em um mundo imagi nário em que se realiza todo tipo de desejos e surgem idéias de perseguição. Ambos os mundos constituem para eles realidade, e às vezes podem mantê-los conscientemente separados. Outras vezes, o mundo autístico é para eles o real, o outro é mera aparência. Os seres humanos autênticos são 'máscaras', 'sombras', etc. Segundo a constelação do momento, e em casos de mediana gravidade, ora um dos mundos está em primeiro plano, ora o outro" (p. 436). 